\title{
The Dynamics of Leech Infestation in Livestock and Control Practices in the North Gondar Zone, Northwest Ethiopia
}

\section{Bodena Gemeda}

University of Gondar Faculty of Veterinary Medicine

Moges Maru ( $\square$ malemayehu19@yahoo.com)

University of Gondar Faculty of Veterinary Medicine

https://orcid.org/0000-0001-7863-2057

Abraham Ayele

University of Gondar Faculty of Veterinary Medicine

Zewdu Seyoum Tarekegn

University of Gondar Faculty of Veterinary Medicine

\section{Gashaw Getaneh Dagnaw}

University of Gondar Faculty of Veterinary Medicine

\section{Seleshi Nigatu}

University of Gondar Faculty of Veterinary Medicine

Abibo Wondie

University of Gondar Faculty of Veterinary Medicine

\section{Elias Kebede}

University of Gondar Faculty of Veterinary Medicine

\section{Tigist Kindie}

University of Gondar Faculty of Veterinary Medicine

\section{Abiy Maru Alemayehu}

University of Gondar College of Medicine and Health Sciences

\section{Nega Yismaw}

UOG: University of Gondar

Shimelis Dagnachew

University of Gondar Faculty of Veterinary Medicine

\section{Research Article}

Keywords: Leech, Livestock, North Gondar Zone, Prevalence, Risk Factors, and Questionnaire Survey

Posted Date: February 7th, 2022

DOI: https://doi.org/10.21203/rs.3.rs-1303783/v1 
License: (c) (i) This work is licensed under a Creative Commons Attribution 4.0 International License. Read Full License 


\section{Abstract}

In developing countries such as Ethiopia, leech infestation is a neglected parasitic disease of livestock. Although such studies are important, little attention has been paid to the occurrence, impact and risk factors of leech infestation in livestock in Ethiopia. The objective of the current study was to assess farmers' knowledge of leech infestation and control practices, and to estimate the prevalence and risk factors of leech infestation in domestic animals in northwestern Ethiopia. A cross-sectional study was conducted in three districts of North Gondar Zone from February 2021 to August 2021. Livestock $(n=2040)$ and 300 respondents for questionnaire survey were randomly selected. According to the results of the questionnaire survey, $98.67 \%$ of the respondents were aware of leech infestation, the effects of leeches and the locally available control methods. Cattle had the highest prevalence (10.08\%), followed by horses $(3.67 \%)$, goats $(2.48 \%)$, and sheep $(2.02 \%)$. Using a chi-square test, a significant association was found between the prevalence of leech infestation and risk factors such as animal species, sex, age, body condition, and season $(p<0.05)$. Observation of the water bodies revealed that leeches become more active when the water becomes slightly warmer due to sunlight, and they become especially active when the animals want to drink from the water. The current results indicate that leech infestation is the biggest problem for livestock in the study areas, so cost-effective and environmentally friendly control methods must be used.

\section{Introduction}

Leech infestation is a neglected ectoparasitic disease that affects livestock and causes significant economic losses to farmers due to loss of productivity, mortality and treatment costs (Ofukwu et al., 2008; Negm-Eldin et al., 2013). Leech infestation, also known as Hirudiniasis in livestock, is caused by bloodsucking, hermaphroditic, egg-laying segmented worms found throughout the world and classified in the phylum Annelida and order Hirudinea (Bam et al., 2016). It is a waterborne disease that infects animals when they drink water contaminated with leeches, while humans become infected when they drink, bathe, swim or walk through water contaminated with leeches. Leeches parasitise in different parts of the body. The mucous membranes of the nostrils and mouth are common predilection sites for aquatic leeches in the bodies of domestic animals (Eguale et al., 20110; Yelken et al ., 2011; Bahmani et al., 2006, 2012 , 2013). Coughing, blood in the nose and mouth, respiratory problems, emaciation and anaemia, and reduced milk yield have been reported in leech-infested animals (Amsalu et al., 2019; Belay et al., 2013).

The majority of reported cases and prevalence are from developing countries (Yelken et al ., 2011; Behçet et al., 2011; Sarathi et al., 2011; Bahmani et al., 2012). There are few organised and recorded data on the status of leech infestation in Ethiopia. However, unpublished works have identified the leech as one of the country's animal health problems in rural areas. According to the few but scattered study reports in Ethiopia, leech infestation of livestock is common in the highlands, where small streams and ponds are used to water livestock, and the problem occurs mainly during dry seasons (Lemma, 1984; Eguale et al., 2010; Amsalu et al., 2019; Cherinet, 2000). 
Leech infestation has been reported as one of the priority animal health problems in Amhara Administrative Region, where more than two million cattle are at risk (Cherinet, 2000). The dynamics of leech infestation in different animal species, seasons and agro-ecological zones have not been studied; thus, the current study is crucial to clarify this issue. Therefore, the objective of this study was to assess farmers' knowledge of leech infestation and control practices, estimate the prevalence of leech infestation in livestock and identify the associated risk factors for leech infestation in North Gondar zone of northwestern Ethiopia.

\section{Methods And Materials}

\section{Study area}

The study was conducted in three districts of North Gondar zone (Debark, Dabat and Adi-Arkay). Debark district consists of 32 administrative kebeles and is located 830 kilometers from Addis Ababa, the capital of Ethiopia. It is located at latitude $13.133^{\circ} \mathrm{N}$ and longitude $37.900^{\circ} \mathrm{E}$, with altitudes ranging from 2712 to 3122 meters above sea level (m.a.s.l.). Annual rainfall in the area ranges between 900 and $1400 \mathrm{~mm}$, with long and short rainy seasons. The average annual minimum and maximum temperatures are $6.2^{\circ} \mathrm{C}$ and $20.7^{\circ} \mathrm{C}$, respectively, and humidity ranges from 25 to $83.5 \%$. Dabat district is 823 kilometers north of Addis Ababa, the capital of Ethiopia. It is located at $12.9814^{\circ} \mathrm{N}$ and $37.7623^{\circ} \mathrm{E}$, with an altitude ranging from 1500 to 3200 m.a.s.l. The average annual rainfall of the district is between 800 and $1400 \mathrm{~mm}$. AdiArkay is located 907 kilometers north of Addis Ababa (the capital of Ethiopia). The altitude of Adi-Arkay is between 1750 and 2100 m.a.s.l. The majority of the population lives on subsistence agriculture and livestock. The town is located on the northern slopes of Ras Dashen, one of the highest peaks in Africa. It is 907 kilometers north of Addis Ababa, the capital of Ethiopia, and 180 kilometers north of the ancient city of Gondar.

\section{Study population}

The study animals include cattle, sheep, goats, horses and donkeys. All age and body condition groups were represented. The age of the animals was estimated from the stage of erupted permanent incisors (Taylor, 1984;Muylle et al., 1999;Yami and Abebe, 2008). Therefore, sheep and goats under 2 years of age were classified as young and over 2 years as adult. Cattle under 3 years of age were classified as adults and over 3 years as young. For horses, animals under 3 years of age were classified as young donkeys, while those over 3 years of age were considered adults. Body condition was graded on a scale of 1-5, where 1) thin, 2) moderate, 3) ideal, 4) fat and 5) obese, based on muscle and fat distribution and the prominence of the spine, hips and ribs Ullman-Culleré et al., 1999). Owners of livestock (cattle, sheep, goats, horses and donkeys) were included in this study as the study population and their bio-data, knowledge, awareness and leech control practices used by the local population were collected using a semi-structured questionnaire.

\section{Study design and Sample size determination}


Data were collected as part of a cross-sectional study from February to August 2021. According to Kothari, (2004), the sample size was calculated using an expected prevalence (Pexp) of $50 \%$, a required absolute precision (d) of $5 \%$ and a confidence level of $95 \%$. Consequently, 384 study animals from each district were considered for the sample. However, to increase precision, the sample size was increased to 684 (342 cattle, 144 sheep, 124 goats, 56 horses and 18 donkeys), 675 (271 cattle, 165 sheep, 95 goats, 60 donkeys and 84 horses) and 681 (349 cattle, 38 sheep, 185 goats, 15 horses and 94 donkeys) for Debark, Dabat and Adi-Arkay districts, respectively, based on the size of the domestic animal population.

The sample size for the questionnaire survey was calculated using the formula ofArsham, (2002), where: $\mathrm{N}=0.25 / \mathrm{SE} 2$, where: $\mathrm{N}=$ sample size, e (standard error $=5 \%$ ), the required sample size for the

questionnaire survey is 100 per district in the study areas according to the above formula. As a result, 300 households were interviewed in all three districts.

\section{Sampling technique}

Simple random sampling by lot was used to select three kebeles from each district. At the final study site, the kebele or village, the study animals were grouped based on their species and a simple random lottery procedure was used to select the animals. In each of the three districts, 962 cattle, 347 sheep, 404 goats and 327 horses (172 donkeys and 155 horses) were selected. Livestock owners in the three districts were interviewed, with only three kebeles from each district. A total of 100 households were selected and interviewed in each district. In each of the households where livestock were interviewed, there was one respondent. This could be any household member if the head of the household was not present. Thus, 33 or 34 households were randomly selected from the total number of households in each kebele to collect data using a questionnaire.

\section{Sampling procedure}

\section{Collection and transport of leeches}

The study animals were physically examined (close observation or inspection) to detect signs of leech infestation such as cough, bloody sialorrhea and/or reddish discoloration of the lower lip. These animals were castrated and/or restrained and their preferred sites for leech infestation (oral cavity and nostrils) were visually inspected for signs of leech infestation. The leeches were then severed and removed with tweezers, stored in a plastic universal bottle of well water and labelled with the necessary information. In addition, water bodies such as small streams, irrigation canals and wells that were potential sources of leech infestation for animals were surveyed under the supervision of people who were well versed in the area. The survey for leeches was based on searching under stones at the water's edge (where water flow was not high) and on fine grass and other objects (such as plastic submerged in the periphery of water bodies) lying in the water. The collected leeches were kept in universal plastic bottles labelled with the necessary information for morphological identification. The collected leeches from animals and water 
bodies were transported in an icebox to the Veterinary Parasitology Laboratory of the University of Veterinary Medicine and Animal Sciences, University of Gondar, where they were morphologically identified.

\section{Questionnaire survey}

A semi-structured questionnaire was used to conduct face-to-face interviews in a local Amharic language to assess awareness, knowledge, practices and attitudes towards leech infestation in domestic animals. Using this questionnaire, baseline data were collected including socio-demographic characteristics, domestic animal species kept, farmers' knowledge and awareness of leeches, clinical signs in animals, leech-infested water bodies and leech control practices.

\section{Morphological identification}

In the laboratory, the leeches were examined with a stereomicroscope and photographed with a smartphone camera mounted directly on the stereomicroscope. The morphological structures of the leeches were characterized and evaluated using the morphological identification keys described in (Negm-Eldin et al., 2013; Arfuso et al., 2019). The morphological structures were observed and assessed, including colour, size and shape, number of segments, jaw shape and external openings. The data were recorded on a data collection sheet. The leech was caught from the bottle with tweezers and placed on the petri dish. Drops of $95 \%$ alcohol were then added to reduce the activity and movement of the leech. The required body parts of the leech were then examined.

\section{Data management and analysis}

SPSS version 20 was used to analyse the recorded data. Mean, proportion and percentage (frequencies) were to be used to calculate the prevalence of leech infestation. Chi-square test was used to test the relationship between leech infestation and risk factors for leech infestation and the association was considered significant when the $P$-value was less than $0.05(P<0.05)$.

\section{Results}

\section{Respondents' knowledge of Leech Infestation and the methods used to control it}

Three hundred participants took part in this questionnaire survey to determine their knowledge and awareness of leech infestation in pets. As a result, $98.67 \%$ (296/300) of the respondents indicated that they were aware of leech infestation in livestock. Majority of the respondents in this study were above 45 years of age ( $47.0 \%)$, followed by those aged $35-45$ years (29.3\%), 26-35 years (17.7\%) and $12-25$ years (6.0\%). In terms of education level of the respondents, $53.7 \%$ had no formal education while the others were literate with different educational backgrounds: adult education (29.7\%), religious education (7.33\%), primary school (6.67\%) and secondary school (2.7\%). Furthermore, in this survey, the majority of respondents $(74.7 \%)$ had lived in the study area for more than 20 years, while only $6 \%$ had lived there for a short time (0-5 years). 
A chi-square test was used to examine the relationship between the demographic characteristics of the respondents and their knowledge about leech infestation in livestock. The result was that knowledge about leech infestation and respondents' profiles such as length of residence in the study area, position in the family and age were significantly associated $(p<0.05)$ (Table 1$)$. For example, residents who had lived in the study area for 0-5 years knew less about leech infestation than those who had lived there for $6-10,11-20$ and more than 20 years $(c 2=63.514 ; p<0.001)$. Respondents from Dabat district were most knowledgeable about the presence of leech infestation in livestock, followed by respondents from Debark (99.99\%) and Adi-Arkay (97.0\%) districts.

Table 1: Cross-tabulation of knowledge status and socio-demographic profile of respondents 


\begin{tabular}{|c|c|c|c|c|c|}
\hline $\begin{array}{l}\text { Sociodemographic } \\
\text { factor }\end{array}$ & Category & $\begin{array}{l}\text { Participated } \\
\text { respondents (\%) }\end{array}$ & $\begin{array}{l}\text { Having Leech } \\
\text { infestation knowledge } \\
\mathrm{n}(\%)\end{array}$ & $x^{2}$ & $P$-value \\
\hline \multirow[t]{4}{*}{ Age (year) } & $12-25$ & $18(6.0)$ & 15(83.3) & \multirow[t]{4}{*}{35.387} & \multirow[t]{4}{*}{.000} \\
\hline & $26-35$ & $53(17.7)$ & $52(91.1)$ & & \\
\hline & $36-45$ & $88(29.3)$ & $88(100)$ & & \\
\hline & $>45$ & $141(47.0)$ & $144(100)$ & & \\
\hline \multirow[t]{2}{*}{ Sex } & Male & $290(96.7)$ & 287(99) & \multirow[t]{2}{*}{5.906} & \multirow[t]{2}{*}{0.15} \\
\hline & Female & $10(3.3)$ & $9(90)$ & & \\
\hline \multirow[t]{3}{*}{ Position in family } & Male head & $280(93.3)$ & 279(99.6) & \multirow[t]{3}{*}{32.305} & \multirow[t]{3}{*}{.000} \\
\hline & Female & $9(3.0)$ & $8(88.9)$ & & \\
\hline & $\begin{array}{l}\text { Family } \\
\text { member }\end{array}$ & $11(3.7)$ & $9(81.8)$ & & \\
\hline \multirow[t]{5}{*}{ Education } & Primary & $20(6.7)$ & $20(100)$ & \multirow[t]{5}{*}{3.50} & \multirow[t]{5}{*}{0.623} \\
\hline & Secondary & $8(2.7)$ & $8(100)$ & & \\
\hline & Adult & $89(29.7)$ & $89(100)$ & & \\
\hline & No formal & $161(53.7)$ & 157(98.7) & & \\
\hline & $\begin{array}{l}\text { Religious } \\
\text { (Kes) }\end{array}$ & $22(6.7)$ & $22(100)$ & & \\
\hline \multirow[t]{3}{*}{ District } & Debark & 100(33.33) & $99(99.0)$ & \multirow[t]{3}{*}{3.547} & \multirow[t]{3}{*}{0.170} \\
\hline & Dabat & 100(33.33) & $100(100)$ & & \\
\hline & Adi-Arkay & 100(33.33) & $97(97.0)$ & & \\
\hline \multirow[t]{4}{*}{ Stay period (year) } & $0-5$ & $18(6.0)$ & 14(77.8) & \multirow[t]{4}{*}{63.514} & \multirow[t]{4}{*}{0.000} \\
\hline & $6-10$ & $30(10.0)$ & $30(100)$ & & \\
\hline & $11-20$ & $28(9.33)$ & $28(100)$ & & \\
\hline & $>20$ & $224(74.70)$ & $224(100)$ & & \\
\hline
\end{tabular}

\section{Practices to control leech infestation}

Coughing, bleeding from the mouth, emaciation and enlargement of the neck area were reported by $98.67 \%$ of the respondents in leech infested animals. The local people in the study areas had applied 
various treatment, control and preventive measures to alleviate the problem of leech infestation in domestic animals. Manual removal of the leech, restricting drinking water to their animals below the ideal daily dose for 2-3 days, transport to veterinary clinic, watering with salt water and honey, watering with crushed and dissolved leaves of 'Lenquata', 'Swaria' and 'Timbaho' are some of the measures taken by the respondents for sick animals infested with leech. Table 2 shows the percentages of respondents who indicated different treatment options.

Respondents indicated that animals do not have direct access to leech-infested water or waterlogged pastures as a preventive measure. They also indicated fetching water and using water troughs to give water to their animals after filtering it with a towel. In addition, 166 respondents (53.33\%) had used Birbira leaves and seeds, Swaria leaves, Endod leaves and Kikita leaves to treat contaminated water. According to the respondents, these medicinal plant parts (leaves and seeds) are crushed and dissolved in water. The solutions are then applied directly to the water bodies at night when the animals return to their homes. However, 130 (43.33\%) respondents who were aware of leech infestation did not know how to control or manage it in the water bodies (Table 2).

Table 2: Treatment and management practice leech infestation in animals and water bodies.

\begin{tabular}{|c|c|c|c|}
\hline $\begin{array}{l}\text { Treatment } \\
\text { on }\end{array}$ & Treatment Method & Application rout & $\begin{array}{l}\text { Respondent number } \\
\mathrm{n}(\%)\end{array}$ \\
\hline \multirow[t]{8}{*}{ Animals } & Manual removal & Oral cavity \& nasal & $82(27.33)$ \\
\hline & Water intake frequency reduction & - & $51(1)$ \\
\hline & Saltwater drenching & oral & $15(5)$ \\
\hline & Veterinary clinic & - & $54(18)$ \\
\hline & Lenquata leaf(Grewia ferruginea) & oral \& nasal & $37(12.3)$ \\
\hline & Swaria leaf & oral \& nasal & $30(10)$ \\
\hline & Honey drenching & oral and nasal & $20(6.7)$ \\
\hline & Tembaho smocking & nasal & $7(2.3)$ \\
\hline \multirow[t]{5}{*}{$\begin{array}{l}\text { Water } \\
\text { bodies }\end{array}$} & $\begin{array}{l}\text { Birbra leaf \& seed (Milletia } \\
\text { ferruginea) }\end{array}$ & $\begin{array}{l}\text { directly on water } \\
\text { body }\end{array}$ & 10(3.33) \\
\hline & Suarea leaf & & 143(47.67) \\
\hline & $\begin{array}{l}\text { Endod leaf (Phytolacca } \\
\text { dodecandera) }\end{array}$ & $\begin{array}{l}\text { directly on water } \\
\text { body }\end{array}$ & 10(3.33) \\
\hline & $\begin{array}{l}\text { Kitkita leaf (Dodonaea } \\
\text { angustifolia) }\end{array}$ & $\begin{array}{l}\text { directly on water } \\
\text { body }\end{array}$ & $3(1)$ \\
\hline & No treatment before & - & $130(43.33)$ \\
\hline
\end{tabular}




\section{Source of leech infestation and body parts of leech infestation}

Small rivers, wells, irrigation canals and standing water bodies were reported by the respondents as the primary sources of water for livestock in the study areas. If their livestock have direct access to infested water bodies, these become a source of leech infestation. According to the respondents, livestock become infected with the parasite when they drink water from leech-infested water bodies and graze on leechinfested deforested areas. They also stated that leeches are more common during the dry season, especially from mid-December to June. They also indicated that cattle are the most vulnerable species, regardless of sex or age. Forty-four per cent of the respondents with knowledge of leech infestation in animals $(296 / 300)$ found leech infestation under the tongue, on the gums $(28.7 \%)$, hanging in the nose $(24.7 \%)$ in live animals and in the sinuses and throat (1.7\%) in slaughtered animals (Table 3 ).

Table 3. Respondents' perception about site of leech infestation in animals body parts

\begin{tabular}{|ll|}
\hline Site of infestation & Response rate $\mathrm{n}(\%)$ \\
\hline The base of under the tongue & $132(44.0)$ \\
\hline Attached to gum & $85(28.7)$ \\
\hline Suspended to nose & $74(24.7)$ \\
\hline Inside sinuses and throat after slaughter & $5(1.7)$ \\
\hline
\end{tabular}

\section{The effects of leech infestation}

The respondents in the three districts were of the opinion that leech infestation has direct impact on animal health and indirect impact on financial and social aspects (Table 4). According to the respondents, leech infestation was more pronounced during the dry season when the volume of water bodies decreased. In addition, sick animals, especially cattle, reduced milk yield, emaciation and respiratory problems, and in rare cases deaths are the causes of loss of livestock production, according to the respondents.

Furthermore, 5.3 percent of respondents said they had a leech infestation at least once in their lives. They described clinical symptoms such as cutaneous bleeding, blood-tinged saliva, and shortness of breath after coming into contact with an irrigation canal while working. They remembered that they used both traditional and modern medication methods to alleviate the problem. The traditional intervention method they used was manual removal, and the treatment option they preferred to alleviate the problem was smoking of dried and rolled tobacco leaf powder.

Table 4: Social and financial impact of leech infestation 


\begin{tabular}{|lll|}
\hline Variable & Category & Respondents' number $\mathbf{n}(\%)$ \\
\hline Social impact & Feeling the animal pain & $240(80.0)$ \\
\cline { 2 - 3 } & Conflict with herd man & $31(10.33)$ \\
\cline { 2 - 3 } & $\begin{array}{l}\text { Looking other's hand for animal } \\
\text { treatment }\end{array}$ & $21(7.0)$ \\
\hline Financial & Combination the above & $4(1.33)$ \\
impact & Production decrease & $198(66.0)$ \\
\cline { 2 - 3 } & Veterinary cost & $45(15.0)$ \\
\cline { 2 - 3 } & Wastage of work time & $23(7.67)$ \\
& loss of animal & $16(5.33)$ \\
& Combination of the above & $14(4.67)$ \\
\hline
\end{tabular}

\section{Prevalence and associated risk factors of leech infestation}

In livestock, the overall prevalence of leech infestation was 6.2\% (126/2040). Cattle had the highest prevalence $(10.08 \%)$, followed by equine (horse) $(3.67 \%)$, goats $(2.48 \%)$, and sheep $(2.02 \%)$. Lower and higher prevalence $(\mathrm{L} ; \mathrm{H})$ were found in Zebena and Debir (3; 7.9\%), Woken and 02 (4.5; 5.7\%), and Adi argay and Abamar (7.0; 9.5\%) Kebele of the Debark, Dabat, and Adi Arkay districts, respectively (Table 5).

Table 5: Prevalence dynamics of leech in study districts' kebeles 


\begin{tabular}{|llll|}
\hline Districts & Kebeles & No.animals examined & Leech positive animals no (\%) \\
\hline Debark & Dibbahir & 226 & $10(4.40$ \\
& Zebena & 230 & $7(3.0)$ \\
\hline & Debir & 228 & $18(7.9)$ \\
\hline Dabat & Woken & 221 & $10(4.7)$ \\
& 02 & 227 & $13(5.7)$ \\
\hline Adi-Arkay & Abamar & 220 & $12(5.2)$ \\
\hline & Adi-argay & 228 & $21(9.5)$ \\
\hline Total & 01 kebele & 233 & $16(7.0)$ \\
\hline
\end{tabular}

The oral cavity (under the base of the tongue, on the gum) was the preferred infestation site of the leeches in animal body parts, with a prevalence of $96(4.71 \%)$ and the nostril with a prevalence of $1.47 \%$ (30). The following risk factors were identified in this study: animal species, animal sex, age, body condition, season, and district. The prevalence of leech infestation and associated risk factors such as animal species, sex, age, body condition, and season varied significantly $(p<0.05)$ (Table 6). Henceforth, cattle (10.08\%) had the highest prevalence, followed by equine (in horses only) (3.67\%), goats (2.48\%), and sheep $(2.02 \%)(\mathrm{c} 2=34.303 ; p<0.001)$, and poor body conditioned animals $(8.9 \%)$ had the highest prevalence, followed by medium (6.1\%) and good body conditioned animals ( $3.8 \%$ ) (c2 = 15.484; $p<$ 0.001). Furthermore, Table 6 revealed that females (7.4\%), adults $(6.4 \%)$, and dry season $(7.67 \%)$ had higher prevalence than males, young, and short rainy season, in terms of risk factors such as sex, age, and season. Another factor that had a statistically significant impact on the occurrence of leech infestation in cattle was breed $(p<0.05)$. Crossbreds were found to have a lower prevalence $(6.97 \%)$ than local breeds (8.81\%).

Table 6: Association of risk factors and prevalence of leech infestation in livestock 


\begin{tabular}{|c|c|c|c|c|c|}
\hline Factor & & no of examined & no positive & $x^{2}$ & p-value \\
\hline \multirow[t]{4}{*}{ Species } & Cattle & 962 & $97(10.08 \%)$ & & \\
\hline & Sheep & 347 & $7(2.02 \%)$ & & \\
\hline & Goats & 404 & $10(2.48 \%)$ & & \\
\hline & Equine & 327 & $12(3.67 \%)$ & 34.303 & 0.000 \\
\hline \multirow[t]{3}{*}{ Boy condition } & Good & 741 & $28(3.78 \%)$ & & \\
\hline & Medium & 628 & $38(6.05 \%)$ & & \\
\hline & Poor & 671 & $60(8.94 \%)$ & 15.484 & 0.000 \\
\hline \multirow[t]{2}{*}{ Sex } & Male & 929 & $44(4.7 \%)$ & & \\
\hline & Female & 1111 & $82(7.4 \%)$ & 6.106 & 0.008 \\
\hline \multirow[t]{2}{*}{ Season } & short rain & 844 & $23(2.73 \%)$ & & \\
\hline & Dry & 1196 & $92(7.69 \%)$ & 15.484 & 0.000 \\
\hline \multirow[t]{3}{*}{ District } & Debark & 684 & $35(5.12 \%)$ & & \\
\hline & Dabat & 675 & $35(5.19 \%)$ & & \\
\hline & Adi-Arkay & 681 & $56(8.22 \%)$ & 13.844 & 0.086 \\
\hline \multirow[t]{2}{*}{ Age } & Young & 232 & $11(4.74)$ & & \\
\hline & Adult & 1808 & $115(6.36 \%)$ & 0.930 & 0.0209 \\
\hline
\end{tabular}

\section{Survey of leech-infested water bodies}

During the study period, nine water bodies were surveyed and observed for the presence of leeches. However, because this was an observational survey, the number of leeches could not be estimated. In each kebele, one body of water was observed. Small streams, stagnant water, and well water were the most common types of water bodies. Leeches were discovered in a variety of niches in the surveyed water bodies, including inside less movable water bodies, under stones near and inside water bodies, on grass hanging over water bodies, and inside muddy areas near water bodies. During the observation, leeches in water bodies became active when the water became slightly warmer when exposed to direct sunlight, and they became extremely active when they sensed the arrival of warm-blooded animals.

\section{Morphological Identification of leech}

A stereomicroscope was used to examine leeches collected from infested animals and water bodies. The leeches studied in this study were $2-3.0 \mathrm{~cm}$ long and $0.5-1.0 \mathrm{~cm}$ wide (Fig.1A), with a brown, dark green- 
black color on the dorsal side and a lighter color on the ventral side. The anterior end is more tapper than the posterior end. The diameter of the well-developed posterior sucker (Fig. 1B) was equal to the maximum width of the body $(1 \mathrm{~cm})$. The anterior sucker had ten eyespots that were arranged in lateral crescents (Fig. 1C). Inside the oral cavity, triple jaws, one dorsomedial and one asymmetrical pair of ventrolateral, were observed and surrounded the oral opening (Fig. 1D). The jaws looked rounded, soft, and light, gluing foamy things with clearer spots. As a result, all of the recovered leeches at the genus level were identified as Limnatis based on the morphological features observed here (Fig. 1).

\section{Discussion}

\section{Respondents' knowledge, awareness, and control practices}

According to the results of a questionnaire survey, all respondents (100\%) in Dabat district, $99.0 \%$ and 97.0\% in Debark and Adi-Arkay districts, respectively, have knowledge and awareness about leech infestation in livestock. A total of 296 respondents (96.67\%) are aware of and knowledgeable about leech infestation. The remaining 1.3 percent (4/300) of respondents, however, were unaware of the leech infestation. Similar study reports from Ethiopia (Amsalu et al., 2019) and Tanzania (Nyamsingwa, 2016) found that livestock owners are well-versed and aware of leech infestations in both animals and humans. The majority of interviewees in this study were over the age of 45 (47.0\%), followed by those aged 35-45 (29.3\%), 26-35 years (17.7\%), and $12-25$ years (6.0\%). In terms of educational backgrounds, $53.7 \%$ of respondents had never had formal education, while others could read and write from a variety of educational backgrounds (adult education, $29.7 \%$; religious, $7.33 \%$; primary, $6.67 \%$; and secondary, $2.7 \%$. Furthermore, in this survey, the majority of interviewees $(74.7 \%)$ had lived in the study area for more than 20 years, while only $6 \%$ had lived there for a short period ( $0-5$ years).

The respondents' knowledge of leech infestation and demographic profiles such as stay duration in the study area, position in the family, and age were significantly associated $(p<0.05)$. Residents who have stayed for a longer period and are older than 25 years, as well as those with formal and religious education, are more knowledgeable and aware of the leech infestation and the effects it has on livestock. For example, residents who lived in the study area for 0-5 years were less knowledgeable about leech infestation than those who lived there for $6-10,11-20$, and more than 20 years $(\chi 2=63.514 ; p<0.001)$. This could be because the respondents may have recently joined the family member as a herdsman or as a housewife from a leech-free area at the time of the interview. Furthermore, male heads (99.6\%) knew more about leech infestations than female heads (88.9\%) and family members $(81.8 \%)(\mathrm{X} 2=32.303 ; p<$ $0.001)$. In this survey, it was also noticed that respondents aged $>45$ years $(100 \%)$ and $36-45$ years were more knowledgeable than those aged 26-35 years (91.1\%), followed by those aged 12-25 years (83.3\%). This could be because the respondents would be more knowledgeable if they had lived in the study area for a longer period.

Regarding the severity of the disease depending on the season and the species, respondents indicated that leeches are more common in the dry season, especially from mid-December to June, and cattle are 
the most vulnerable species regardless of sex or age. Due to the dry season, the volume of small streams, wells, traditional irrigation canals, spring water, pump water, and stagnant water has decreased, and these water bodies are the source of water from which domestic animals drink. According to the respondents, the sources of leech infestation in domestic animals are leech-infested water bodies and waterlogged or deforested pastures that become infested with leech-infested water and grasses or other edible plants after drinking and grazing. Furthermore, respondents are not only aware of the seasonal and significant impact of the parasite on cattle, but they are also able to recognize the clinical signs of leech infestation in animals. According to the respondents (98.67\%), infected animals showed clinical signs of leech infestation such as coughing, bleeding from the mouth, emaciation, and swelling in the neck area. In addition, 217 respondents reported collected leeches in the oral cavity, including under the base of the tongue ( $n=132$ of them) and on the gums ( $n=85$ of them), as well as in the nasal cavity, suspended from the nose ( $n=74$ of them) and in the sinuses and pharynx at autopsy ( $n=5$ of them).

According to the respondents, local people in the study areas apply a variety of treatment, control, and preventive measures to alleviate the problem of leech infestation in animals. Measures taken by respondents for sick leech-infested animals included manual removal of the leech, restricting the drinking water supply of their animals to an amount 2-3 days below the ideal daily dose, going to the veterinary clinic, watering with salt water and dissolved honey, watering with crushed and dissolved leaves of Grewia ferruginea (Lenquata, local name in Amharic), swaria, and Nicotiana tabacum (Tembaho). In addition, respondents indicated that, as a preventive measure, animals do not have direct access to leechinfested water bodies or waterlogged pastures. They also indicated that they fetch water troughs and use them to give water to their animals after filtering it with a towel. In addition, 166 respondents (53.33\%) had used Millettia ferruginea (Birbira) leaves and seeds, swaria leaves, Phytolacca dodecandera (Endod) leaves, and Dodonaea angustifolia (Kikita) leaves to treat polluted water. According to the respondents, these medicinal plant parts (leaves and seeds) are crushed and dissolved in water. The solutions are then applied directly to the bodies of water at night when the animals return to their homes. However, 130 (43.33\%) of the respondents who knew about leech infestation had no idea about leech control and water body management options.

The respondents in the three districts believed that leech infestations had a direct impact on animal health and an indirect impact on products by reducing the drought power of working animals, and thus the owners faced financial and social consequences. All of these effects, according to the interviewees, are exacerbated during the dry season, when the volume of water bodies decreases. Furthermore, sick animals, particularly cattle, reduced milk yield, emaciation, and respiratory issues, as well as, in rare cases, fatalities, are the causes of animal production losses, according to respondents.

What's more, $5.3 \%$ of respondents said they had a leech infestation at least once in their lives. They described clinical symptoms such as cutaneous bleeding, blood-tinged saliva, and shortness of breath after coming into contact with an irrigation canal while working. They remembered that they used both traditional and modern medication methods to alleviate the problem. The traditional intervention method 
they used was manual removal, and the treatment option they preferred to alleviate the problem was the smoking of dried tobacco leaf powder.

\section{Prevalence and risk factors of Leech infestation}

Leech infestation was found to be $6.2 \%$ of the time in livestock. Cattle had the highest prevalence of the study animals (10.08\%), followed by equines (horse) (3.67\%), goats $(2.48 \%)$, and sheep $(2.48 \%)(2.02 \%)$. This difference was statistically significant $(p<0.05)$. This could be because cattle consume more water, potentially exposing them to a higher risk of leech infection. Furthermore, the prevalence was higher in the dry season (7.69\%) than in the short rainy season (2.73\%). Among the study districts, Adi-Arkay (8.22\%) had a higher prevalence than Dabat (5.19\%) and Debark (5.12\%), but there was no statistically significant difference $(P>0.05)$.

During the physical examination of positive animals, the oral cavity (base of the tongue and gum) had a $4.71 \%$ prevalence of leech and the nostrils had a $1.47 \%$ prevalence of leech. On-site preference of leeches on animal body parts was found to be statistically significant $(P<0.05)$. Amsalu et al., $(2019)$ found $4.9 \%$ of infected animals in the mouth and 1.7\% in the nostrils in Ethiopia, and Al-Ani et al., (1995) observed 8 L. nilotica attached to one camel's nasal cavity in Iraq. Furthermore, Moghaddar et al., (2011) reported 19 leeches as a cause of fatal hirudiniasis in cattle in Iran (four leeches removed from the nostrils, 15 at necropsy). Similarly, Bahmani et al., (2012) collected 6-7 blood-sucking leeches from sheep esophagus, and Singhal et al., (2002) reported three blood-sucking leeches from the nose as the cause of epistaxis in a single patient.

The current finding has a higher overall prevalence than Amsalu et al., (2019) who reported an overall prevalence of $3.4 \%$ in livestock (cattle, sheep, goats, and equine) in Ethiopia, and a lower overall prevalence than Nyamsingwa, (2016), who reported a zero prevalence in cattle in Tanzania, and a higher overall prevalence than Negm-Eldin et al. (2013), who reported a prevalence of $11.41 \%$ in farm animals in Libya.

Various risk factors were identified in this study: animal species, sex, age, body condition, season, and district. The prevalence of leech infestation and associated risk factors such as animal species, gender, age, body condition, and season were significantly associated $(P<0.05)$. The higher prevalence in cattle than in other species of animals is consistent with the findings of Amsalu et al. (2019), who reported a prevalence of $5.2 \%$ in cattle. Low body condition animals had a higher and statistically significant leech prevalence rate, which is consistent with the findings of Amsalu et al. (2019. In contrast to the findings of Amsalu et al. (2019), who found a higher prevalence of male animals than female animals, the current study found a higher prevalence of female animals than male animals. Furthermore, the dry season was more prevalent in the current study than the short rainy season. This could be because the volume of water bodies where animals drink is decreasing, and the temperature of the environment is favourable for the leech to thrive in water bodies. Furthermore, as the volume of water increases, so does its speed, making it more difficult for leeches to settle undisturbed and allowing them to be captured by run-off 
water. When it comes to varying ages, adult animals are more common. This could be due to the sample size and sampling technique resulted in a greater number of adult animals than young animals because age stratification was not performed during sampling. Another factor that had a statistically significant impact on the occurrence of leech infestation in cattle was breed $(P<0.05)$. As a result, cross-breeds had a lower prevalence $(6.97 \%)$ than local breeds $(8.81 \%)$.

Water bodies from which animals drink were surveyed in each study kebele to assess the presence of leeches. As a result, one water body was surveyed in each kebele, and a number of leeches were observed inside water bodies, under stones near water bodies, hanging on grass, and inside muddy areas near water bodies. This observation is consistent with the finding of Nyamsingwa, (2016) in Tanzania and Negm-Eldin et al. (2013) observation in Libya. During the observation, the number of leeches in water bodies increased when the water became slightly warmer after being fully exposed to the sun, and they become extremely active when they detect the arrival of animals to drink from the water body.

\section{Conclusion}

The current study's findings reveal that leech infestation is common and has an impact on animal health and production. Local communities in the study areas are well-versed in leech infestations in livestock. The current discovery suggests the presence of leeches in certain observed water bodies, as well as a higher prevalence of leech infestation in livestock. Leech infestation was found to be more common in cattle and during the dry season. Farmers and local communities drench and apply medicinal plants to cure and control leech infestations in both water bodies and livestock. Although traditional methods appear to produce positive results, more research should be conducted to determine their advantages and disadvantages. As a result, the following recommendations are made based on the conclusion. Researchers, veterinarians, and other concerned bodies should pay special attention to this neglected livestock health problem. Livestock producers should be educated on the benefits and drawbacks of using locally available traditional control methods; the effectiveness of locally available medicinal plants as a control method should be studied further; and environmentally friendly and cost-effective control methods should be implemented.

\section{Declarations}

Acknowledgements: We are greatful to acknowledge the Office of Vice President for research and Community service, University of Gondar for its financial support.

Funding: The Office of Research and Community Services Vice President, University of Gondar, was granted the study (Ref. No. CVMAS/13/64/2020). The funding body played no role in the design of the study, collection, analysis, interpretation of the data, or in writing the manuscript or decision to submit the paper for publication.

\section{Author information}




\section{Affiliations}

Department of Veterinary Paraclinical Studies, College of Veterinary Medicine and Animal Sciences, University of Gondar, P.O. Box: 196, Gondar, Ethiopia

Bodena Gemeda, Moges Maru, Abraham Ayele, Zewdu Seyoum Tarekegn, and Shimelis Dagnachew

Department of Veterinary Epidemiology and Public Helth, College of Veterinary Medicine and Animal Sciences, University of Gondar

Seleshi Nigatu

${ }^{3}$ Department of Biomedical Science, College of Veterinary Medicine and Animal Sciences, University of Gondar

Elias Kebede, Gashaw Getaneh Dagnaw

Department of Veterinary pharmacy, College of Veterinary Medicine and Animal Sciences, University of Gondar, P.O. Box: 196, Gondar, Ethiopia

Abibo Wondie

Department of Optometry, College of Medicine and Health Sciences, University of Gondar, P.O. Box: 196, Gondar, Ethiopia

Abiy Maru Alemayehu

Department of Animal sciences, College of Veterinary Medicine and Animal Sciences, University of Gondar, P.O. Box: 196, Gondar, Ethiopia

Tigist Kindie

Central Gondar Zone Agricultural Office, Gondar, Amhara regional state, Ethiopia

Nega Yismaw

\section{Contributions:}

$\mathrm{MM}$ and $\mathrm{AA}$ designed the study and read the manuscript. BG collected field samples and compiled the data. ZST, GGD, and AM conducted data analysis and interpreted the result. MM, SN and AW drafted the manuscript. All authors read, commented and finally approved the final manuscript.

\section{Corresponding author: Moges Maru: malemayehu19@yahoo.com}

\section{Ethics Declarations}


Conflict of interest: The authors declare no competing interests.

Consent to participate: Voluntarily informed Consent was obtained from the Participants for the questionnaire survey by informing them about the objective of this study. Therefore, questionnaire data were collected after the consent was made between the data collectors and the participants voluntarily.

Data availability: The datasets generated during and/or analysed during the current study are available from the corresponding author on reasonable request.

\section{References}

Al-Ani FK, Al-Shareefi MR (1995) Observation on medical leech (Limnatis nilotica) in camel in Iraq. Journal of Camel Practice and Research 2(2):145.

Amsalu, T., Teshager, N., and Alemu, B. (2019): Assessment of Leeches' Impact on Livestock Productivity in the Selected Districts. Applied Journal of Hygiene. 8(1): 01-11 https://www.idosi.org/ajh/8(1)19/1.pdf

Arfuso, F., Gaglio, G., Ferrara, M.C., Abbate, F., Giannetto, S. and Brianti, E., 2019. First record of infestation by nasal leeches, Limnatis nilotica (Hirudinida, Praobdellidae), from cattle in Italy. Journal of Veterinary Medical Science, pp.19-0247. https://dx.doi.org/10.1292\%2Fjvms.19-0247

Arsham, H., 2002. Questionnaire Design and Surveys Sampling, SySurvey: The Online Survey Tool.

Bahmani, M., Zamani, P., Meshgi, B. and Zadeh, A.R., 2006, June. The first reported infestation in sheep at Limnatis nilotica in Iran. In Sixth National Conference and the First Regional Congress of Parasitology and Parasitic Diseases. Karaj (Vol. 384).

Bahmani, M., Eftekhari, Z., Mohsezadeghan, A., Ghotbian, F. and Alighazi, N., 2012. Leech (Limnatis nilotica) causing respiratory distress in a pregnant cow in llam province in Iran. Comparative Clinical Pathology, 21(4), pp.501-503. https://doi.org/10.1007/s00580011-1236-1

Bahmani, M., Golshahi, H., Ghotbian, F. and Bahmani, F., 2013. Internal hirudiniasis in a hen (Gallus gallusdomesticus) - The first report in literature. Asian Pacific Journal of Tropical Disease, 3(3), pp.232234. https://dx.doi.org/10.1016\%2FS2222-1808(13)60046-8

Bam, J., Islam, S., Bhattacharya, D., Deka, D.K., Kalita, D.J., Sharma, R.K., Pathak, P., Maiti, S., Bera, A.K. and Deb, S.M., 2016. In-vitro effect of some plant extracts on Buffalo leech Hirudinaria manillensis. Indian J Anim Sci, 86, pp.988-990.

Behçet, A.L., Yenen, M.E. and Aldemir, M., 2011. Rectal bleeding due to leech bite: a case report. Turkish Journal of Trauma \& Emergency Surgery, 17(1), pp.83-86. https://doi.org/10.5505/tjtes.2011.75318

Belay, D., Getachew, E., Azage, T. and Hegde, B.H., 2013. Farmers perceived livestock production constraints in Ginchi watershed area: Result of participatory rural appraisal. International Journal of 
livestock production, 4(8), pp.128-134.

Cherinet, T., 2000. Preliminary studies towards strategic control of parasitic leeches using traditional plants in north western part of the Amhara Region of Ethiopia,

Technical research report, Ethiopian Science and Technology Commission pp. 41

Eguale, T., Abie, G., Sahile, M. and Gizaw, D., 2010. Control of aquatic leeches (Lymnatis nilotica) using Phytolacca dodecandra (Endod) in Sodo District, Gurage Zone, Southern Nations, Nationalities and Peoples Region, Ethiopia. Ethiopian Veterinary Journal, 14(2), pp.125-

136. https://doi.org/10.4314/evj.v14i2.63889

Kothari, C.R., 2004. Research methodology: Methods and techniques. New Age International.

Lemma, A., 1984. Background and historical review. Another development in schistosomiasis: the case of Endod for use as a molluscicide. In Phytolacca Dodecandra (Endod): Final Report of the International Scientific Workshop, Lusaka, Zambia, March 1983/editors, Aklilu Lemma, Donald Heyneman, Sitali M. Silangwa. Dublin: Pub. for Zambian Natl Council for Scientific Research by Tycooly Internatl Pub., 1984.

Moghaddar, N., 2011. Fatal hirudiniasis in a cow. Comparative Clinical Pathology, 20(3), pp.205207. https://doi.org/10.1007/s00580-010-0969-6

Muylle, S., Simoens, P., Lauwers, H. and Van Loon, G., 1999. Age determination in mini-Shetland ponies and donkeys. Journal of Veterinary Medicine Series A, 46(7), pp.421-429. https://doi.org/10.1046/j.14390442.1999.00229.x

Negm-Eldin, M.M., Abdraba, A.M. and Benamer, H.E., 2013. The first reported leech infestation by Limnatis nilotica (Savigny 1822) of farm animals in Libya. Travaux de l'Institut Scientifique, Rabat, Série Zoologie, 2013, n49, 33-36

Nyamsingwa, Z.I., 2016. Studies on prevalence and the importance of cattle leech infestation in Ngorongoro district, Tanzania (Doctoral dissertation, Sokoine University of Agriculture).

Ofukwu, R.A., Ogbaje, C.I. and Akwuobu, C.A., 2008. Preliminary study of the epidemiology of ectoparasite infestation of goats and sheep in Makurdi, north central Nigeria. Sokoto Journal of Veterinary Sciences, $7(2)$.

Sarathi, K., 2011. Nasal leech infestation causing persistent epistaxis. Journal of Emergencies, Trauma and Shock, 4(3), p.413. https://dx.doi.org/10.4103\%2F0974-2700.83875

Singhal, S.K. and Dass, A., 2002. Multiple live leeches from nose in a single patient-A rare entity. Indian Journal of Otolaryngology and Head and Neck Surgery, 54(2), pp.154-

155. https://doi.org/10.1007/bf02968741 
Taylor, R.E., 1984. Beef production and the beef industry: a beef producer's perspective. Burgess Publishing Company.

Ullman-Culleré, M.H. and Foltz, C.J., 1999. Body condition scoring: a rapid and accurate method for assessing health status in mice. Comparative Medicine, 49(3), pp.319-323.

Yami, A., and Abebe, G. 2008. Sheep and Goat Management. In Sheep and Goat Production Handbook for Ethiopia. Alemu Yami and R.C. Merkel (Editors). Pp. 38-62.

Yelken, M.K., Okur, M.H. and Yuca, S.A., 2011. Leech Infestation of the Nasopharynx; A Rare Cause of Epistaxis and Hemorrhage. European Journal of General Medicine, 8(2). https://doi.org/10.29333/ejgm/82715

\section{Figures}
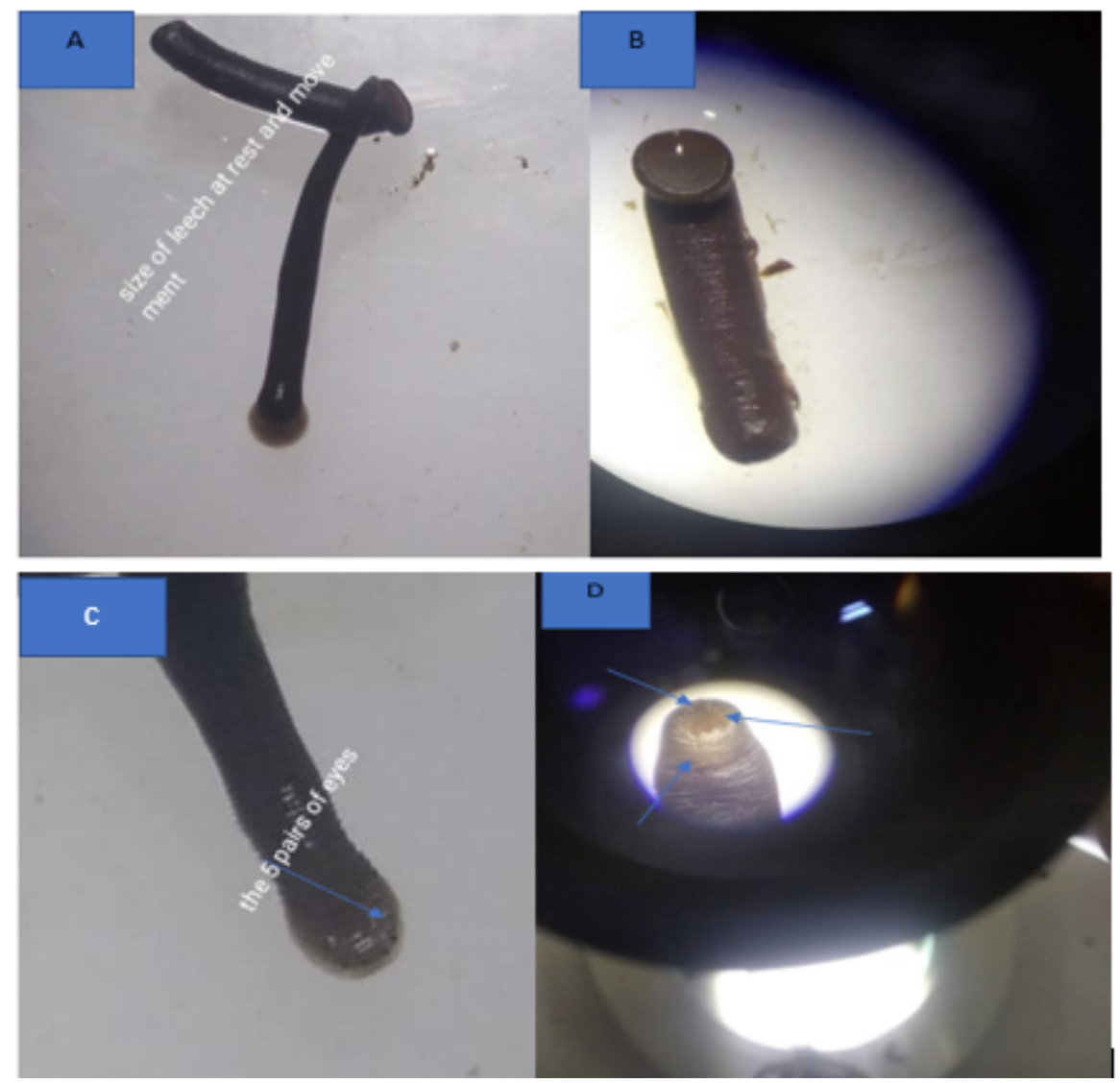

\section{Figure 1}

Morphological features of leech genus Liminits. $A=T$ The approximate length of the leech was measured while it was on the petri dish both at rest $(2.0 \mathrm{~cm})$ and while stretching for movement $(3.0 \mathrm{~cm})$; $B=$ the posterior sucker measured a diameter of the body $1 \mathrm{~cm} ; \mathrm{C}=10$ eyespots arranged in lateral crescent found located at the anterior sucker; and $\mathrm{D}=$ Inside the oral cavity and surrounded the oral opening $\mathrm{Y}$ - 
shaped, triple jaws, consisting of one dorsomedial and asymmetrical pair of ventrolateral jaws were observed. 